\title{
X-RAY FRACTOGRAPHY ON THE FATIGUE FRACTURED SURFACE
}

\author{
疲労破面におけるX線フラクトグラフィ
}

\author{
Shotaro KODAMA, and Koichi AKITA \\ Department of Precision Engineering, \\ Tokyo Metropolitan University, \\ 1-1, Minami-Ohsawa, Hachioji, Tokyo, 192-03, JAPAN \\ TEL : 0426-77-2727 FAX: 0426-77-2717 \\ Accepted 17, October \\ 1991)
}

$\mathrm{X}$-ray fractography is a technique to analyze the cause of the fracture from the X-ray information obtained from the irradiation on the fractured surface. The qualitative relations between the $\mathrm{X}$-ray parameters and the fracture mechanics parameters has been known but quantitative relation is still under development. Through various kinds of load controlling fatigue tests, including constant effective stress intensity factor range tests, a new model for the residual stress distribution was proposed. The quntitative relation between the $\mathrm{X}$-ray and fracture mechanics parameters can be obtaind from this model.

Key words:X-ray fractography, Fracture analysis, Fatigue fractured surface

\section{INTRODUCTION}

The name of X-ray fractography was introduced by Kitagawa and Matumoto ${ }^{1}$ in 1975, and has been developed as a powerfull tool for analyzing the cause of fractures. The electron microscope fractography also has been used successfully in industries. However the $\mathrm{X}$-ray fractography is usueful when the fractured surface was contaminated or oxidized, where the electron microscope fractography is impossible.

The correlation of residual streess on the fractured suface to the fracture mechanics parameters has been known for the high strength brittle materials, ${ }^{2}$ or for ductile materials. ${ }^{3}$

These two types of stress distributions are quite different,but the mechanism to introduce these residual stress distributions must be the same. In our laboratory experimental results under various load control conditions have been accumulated on a structural steel, and an attempt has been made to establish a quntitative evaluation method to predict the residual stress distributions from fatigue loading conditions for ductile materials, for the brittle materials the experiments are now under way.

\section{EXPERIMENTAL PROCEDURE}

The material used was a structural steel (JIS SNCM 439 equivalent to AISI 4340), which was oil quenched after being held at $850^{\circ} \mathrm{C}$ for 30 minutes and tempered at $600^{\circ} \mathrm{C}$. The chemical composition and the mechanical properties after the heat treatment are given in Table 1 and 2 . The specimens were CT with $15 \mathrm{~mm}$-thick and $76 \mathrm{~mm}$-ligament.

Fatigue tests were performed at room temperature in laboratory air by a electrohydraulic testing machine with a sine wave loading. The test frequencies were $5-40 \mathrm{~Hz}$. The fatigue crack opening ratio was measured by the unloading elastic compliance method ${ }^{4}$ Five loading patterns were used, namely the ordinary constant-load-amplitude $(\Delta \mathrm{P})$ test, the constant- $\Delta \mathrm{P}$ on arrested crack test, the decreasing $-\Delta \mathrm{P}$ test, the constant $-\Delta \mathrm{K}$ test, and the constant $-\Delta \mathrm{Keff}$ test. In the constant $-\Delta \mathrm{P}$ on arrested crack test, the load amplitude was decreased until the crack propagation was stopped, then a constant amplitude load was applied to achive a different crack closure condition from the ordinary constant $-\Delta \mathrm{P}$ test of the same load ratio. The relations between the stress intensity factor and the crack length are shown schematically in Figure 1(a)-(d) for each test.

Table 1. Chemical compositions (wt\%)

\begin{tabular}{c|c|c|c|c|c|c|c|c|c}
\hline $\mathrm{C}$ & $\mathrm{Si}$ & $\mathrm{Mn}$ & $\mathrm{P}$ & $\mathrm{S}$ & $\mathrm{Cu}$ & $\mathrm{Ni}$ & $\mathrm{Cr}$ & $\mathrm{Mo}$ & $\mathrm{Al}$ \\
\hline 0.39 & 0.28 & 0.75 & 0.013 & 0.003 & 0.06 & 1.93 & 0.92 & 0.23 & 0.039 \\
\hline
\end{tabular}

Table 2. Mechanical properties

\begin{tabular}{c|c|c|c|c}
\hline $\begin{array}{c}\text { Yield } \\
\text { point } \\
\text { (MPa) }\end{array}$ & $\begin{array}{c}\text { Tensile } \\
\text { strength } \\
\text { (MPa) }\end{array}$ & $\begin{array}{c}\text { Elongation } \\
\text { (\%) }\end{array}$ & $\begin{array}{c}\text { Reduction } \\
\text { of area } \\
(\%)\end{array}$ & $\begin{array}{c}\text { Vickers } \\
\text { hardness }\end{array}$ \\
\hline 880 & 1020 & 16.7 & 60.1 & 324 \\
\hline
\end{tabular}




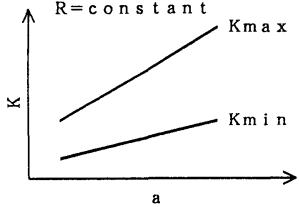

(a)constant $-\Delta \mathrm{P}$ test

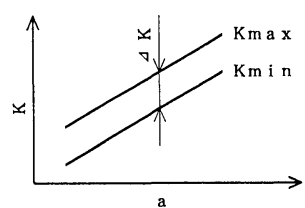

(c)constant $-\Delta \mathrm{K}$ test

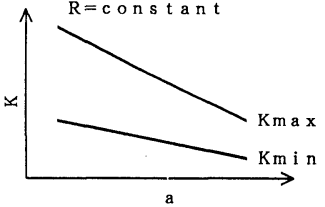

(b)decreasing $-\Delta \mathrm{P}$ test

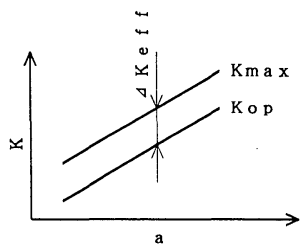

(d)constant $-\Delta$ Keff test
Figure 1. Schematic illustration of stress intensity factor(K) vs. crack length(a).

Table 3. Conditions of $\mathrm{X}$-ray stress measurment

\begin{tabular}{l|l}
\hline Characteristic X-Ray & $\mathrm{Cr}-\mathrm{K} \alpha$ \\
Diffraction plane & $\alpha-\mathrm{Fe}(211)$ \\
Slit divergence angle & 0.35 \\
Filter & $\mathrm{V}$ foil \\
Counter & $\mathrm{Scintillation}$ counter \\
Tube voltage & $30 \mathrm{kV}$ \\
Tube current & $10 \mathrm{~mA}$ \\
Irradiated area & $0.8 \times 6.0 \mathrm{~mm}^{2}$ \\
\hline
\end{tabular}

The residual stress distributions on the fatigue fractured surface were measured by X-Ray diffraction method by the conditions shown in Table 3 .

\section{RESULTS AND DISCUSSION}

\subsection{Crack Propagation Rate $(\mathrm{da} / \mathrm{dN})$}

Figure 2 shows the relation between the $\mathrm{da} / \mathrm{dN}$ and the $\Delta \mathrm{K}$. The results of the ordinary constant $-\Delta \mathrm{P}$ tests are fallen into a band in spite of different load ratios. On the other hand the results of the constant $-\Delta \mathrm{P}$ on arrested crack test, the decreasing $-\Delta \mathrm{P}$ test and the constant $-\Delta \mathrm{K}$ test are not contained in the band because of crack-closure was occured by the effect of the load history.

Figure 3 shows the relation between the $\mathrm{da} / \mathrm{dN}$ and the $\Delta \mathrm{Keff}$. The data points of five fatigue loading patterns are contained in a band, except the data points of less than $5 \mathrm{MPa} \sqrt{\mathrm{m}}$. This result indicates that the $\mathrm{da} / \mathrm{dN}$ is closely related to the $\Delta \mathrm{Keff}$ than the $\Delta \mathrm{K}$.

\subsection{Residual stress distribution}

Figure 4 shows the relation between the residual stress and the Kmax. The data points of solid circle are results of the constant $-\Delta \mathrm{P}$ on arrested crack test. The residual stress are high in the low Kmax range and decrease with increasing Kmax. Therefore in cases of different crack closure behaviors, the residual stress distribution is different even if the load ratios are equal. By indicating the values of the $\Delta \mathrm{Keff}$ on data points in the figure, it was found that the residual stress is higher for the lower $\Delta \mathrm{Keff}$ at each $\mathrm{Kmax}$.

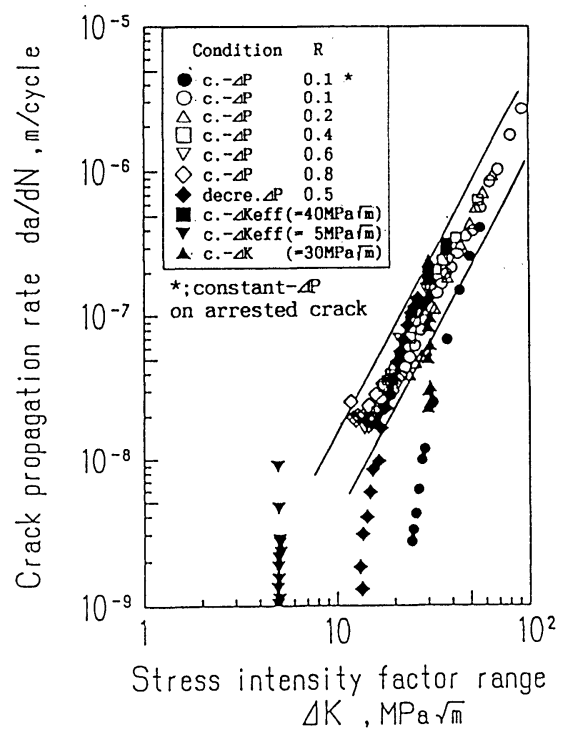

Figure 2. Relation between $\mathrm{da} / \mathrm{dN}$ and $\Delta \mathrm{K}$.

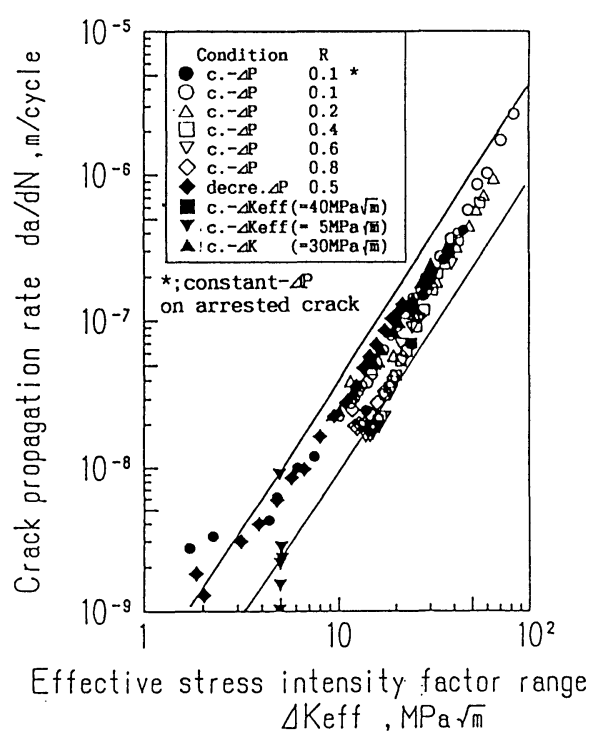

Figure 3. Relation between $\mathrm{da} / \mathrm{dN}$ and $\Delta$ Keff.

Figure 5 shows the relation between the residual stress and the $\Delta \mathrm{Keff}$. The data points fall in a band shown in this figure, except those points with the Kmax lower than $35 \mathrm{MPa} \sqrt{\mathrm{m}}$ or higher than $90 \mathrm{MPa} \sqrt{\mathrm{m}}$. This is interpreted as the residual stress is controlled by $\Delta \mathrm{Keff}$ alone in the range of $35 \leqq K \max \leqq 90 \mathrm{MPa} \sqrt{\mathrm{m}}$.

From these experimental results, when Kmax is less than $35 \mathrm{MPa} \sqrt{\mathrm{m}}$ or more than $90 \mathrm{MPa} \sqrt{\mathrm{m}}$, the residual stress is affected by both $\mathrm{Kmax}$ and $\Delta \mathrm{Keff}$. To separate the effects of Kmax and $\Delta \mathrm{Keff}$ in this range the constant- $\Delta \mathrm{Keff}$ tests were carried out.

Figure 6 shows the residual stress versus the Kmax in the constant- $\Delta$ Keff tests. When $\Delta$ Keff is kept at $5 \mathrm{MPa} \sqrt{\mathrm{m}}$ the residual stress increases 


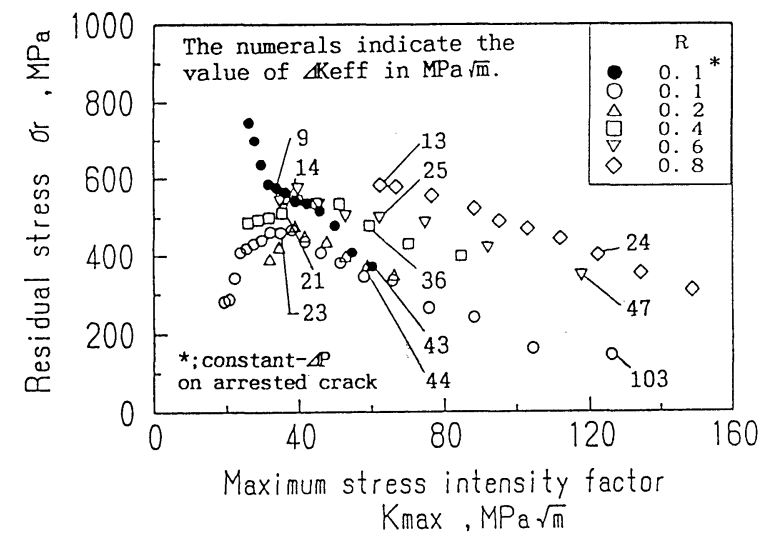

Figure 4. Relation between residual stress and Kmax.

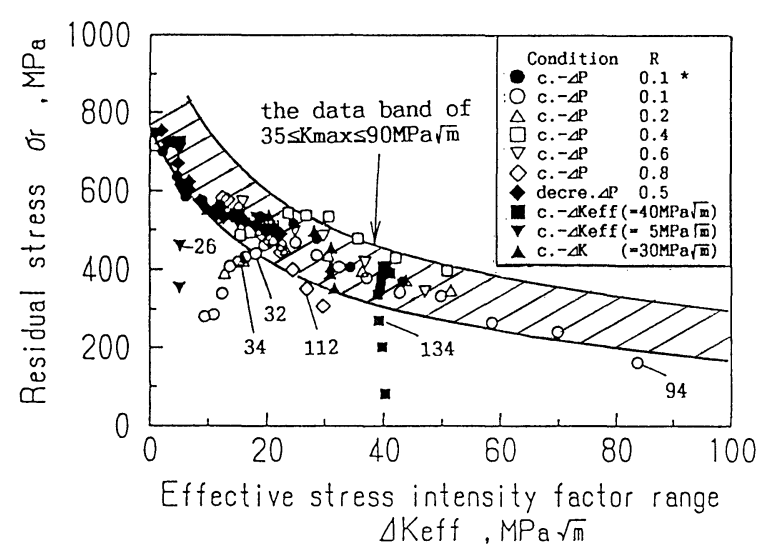

Figure 5.Relation between residual stress and $\Delta$ Keff.

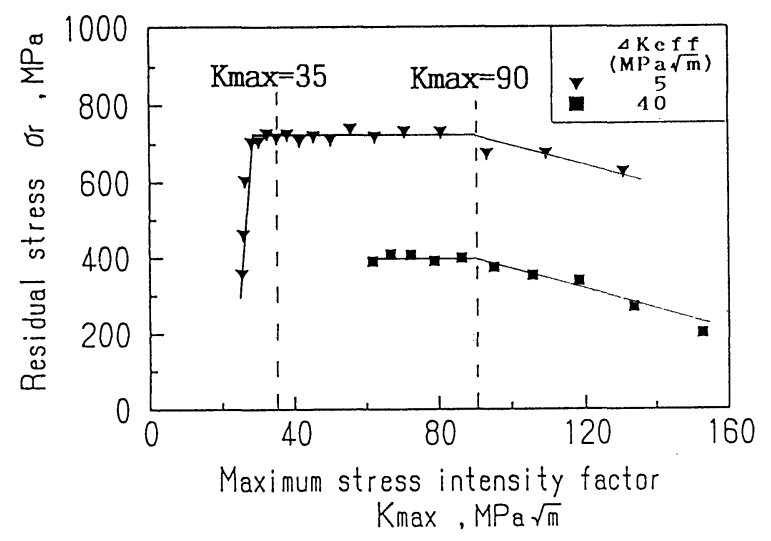

Figure 6. Relation between residual stress and Kmax for constant $-\Delta$ Keff tests.

sharply up to $\mathrm{Kmax}=35 \mathrm{MPa} \sqrt{\mathrm{m}}$, and then becomes nearly constant up to $\mathrm{Kmax}=90 \mathrm{MPa} \sqrt{\mathrm{m}}$ and after that it decreases gradually. When $\Delta$ Keff is kept at $40 \mathrm{MPa} \sqrt{\mathrm{m}}$ the residual stress are nearly constant up to $\mathrm{Kmax}=90 \mathrm{MPa} \sqrt{\mathrm{m}}$ and then decrease gradually.

From the above, the residual stress is higher with higher Kmax in the range of $K \max \leqq 35 \mathrm{MPa} \sqrt{m}$

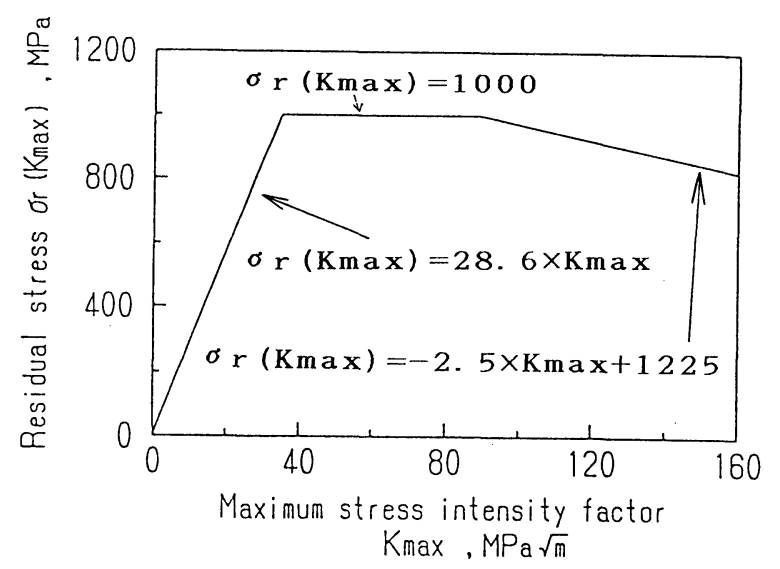

(a)Effect of Kmax

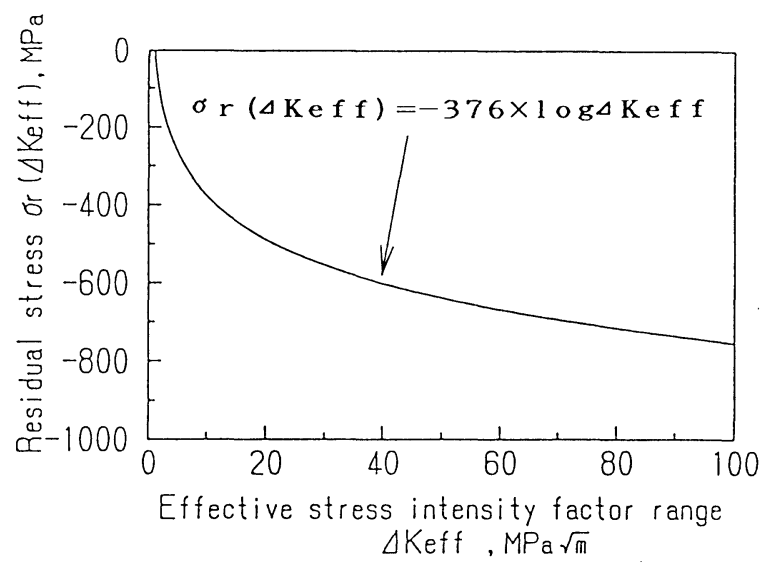

(b)Effect of $\Delta \mathrm{Keff}$

Figure 7.Effect of $\mathrm{Kmax}$ or $\Delta \mathrm{Keff}$ on residual stress.

and always lower with higher $\Delta$ Keff. That is to say, Kmax and $\Delta$ Keff correspond to tensile and compressive residual stress respectively and then the residual stresses are the sum of the both factors. This is shown as follows.

$$
\sigma r=\sigma r(\operatorname{Kmax})+\sigma r(\Delta \mathrm{Keff})
$$

where or:the residual stress on the fractured surface, $\sigma r(K \max )$ :the tensile residual stress controlled by Kmax, or( $\Delta \mathrm{Keff})$ :the compreesive residual stress controlled by $\Delta \mathrm{Keff}$

The correlation of the residual stress and the $\mathrm{Kmax}$ is expressed by three linear functions from Fig.6. When semi logarithmic scales are used the band in Fig.5 is a straight line. These correlation can be shown by eq.(2) and (3) respectively.

$$
\begin{aligned}
& \sigma r(\mathrm{Kmax})=\mathrm{c} 1 \cdot \mathrm{Kmax} \quad(0<\mathrm{Kmax}<35 \mathrm{MPa} \sqrt{\mathrm{m}}) \\
& \sigma \mathrm{r}(\mathrm{Kmax})=\mathrm{c} 2 \\
& \operatorname{\sigma r}(\mathrm{Kmax})=\mathrm{c} 3 \cdot \mathrm{Kmax}+\mathrm{c} 4 \quad(90<\mathrm{K} \max ) \\
& \begin{array}{c}
(0<\mathrm{Kmax}<35 \mathrm{MPa} \sqrt{\mathrm{m}}) \\
(35 \leqq \mathrm{Kmax} \leqq 90 \mathrm{MPa} \sqrt{\mathrm{m}})
\end{array} \\
& \left.\begin{array}{c}
(35 \leqq K \max \leqq 90 \mathrm{MPa} \sqrt{\mathrm{m}}) \\
(90<\mathrm{K} \max )
\end{array}\right\}(2) \\
& \sigma \mathrm{r}(\Delta \mathrm{Keff})=\mathrm{c} 5 \cdot \log \Delta \mathrm{Keff}
\end{aligned}
$$


where, Kmax :(MPa $\sqrt{m}), \Delta \operatorname{Keff}:(\mathrm{MPa} \sqrt{\mathrm{m}}), \quad \mathrm{c1} \sim \mathrm{c5}:$ the experimental constants $(\mathrm{c} 1=28.6, \quad \mathrm{c} 2=1000$, $\mathrm{c} 3=-2.5, \mathrm{c} 4=1225, \mathrm{c} 5=-376$ )

Figure 7 (a) and (b) show these equations (2) and (3). Comparing the calculated values and the experimental results, they agree well as can be seen in Fig.8, for example. Equations (1),(2), and (3) are consistent in spite of various conditions of crack-closure. The contact effect of two fractured surfaces can be ignored within this experimental conditions.

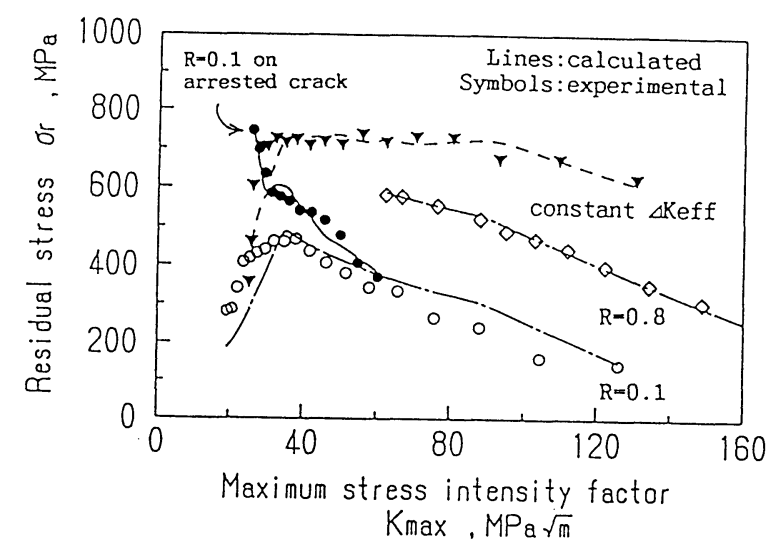

Figure 8.Results of estimation of residual stress.

\section{CONCLUSIONS}

The quantitative analysis technique of the correlation of the residual stresss on the fatigue fractured surface and the Kmax or $\Delta$ Keff was proposed. The main conclusions obtained are as follows.

1. In spite of different load controlling method and load history, the correlation of the residual stress on the fractured surface and the Kmax or $\Delta \mathrm{Keff}$ is expressed by the following equations.

$$
\sigma \mathrm{r}=\sigma \mathrm{r}(\mathrm{Kmax})+\sigma \mathrm{r}(\Delta \mathrm{Keff})
$$

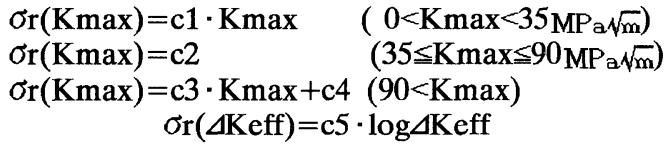

c1 c5 : the experimental constants $(\mathrm{c} 1=28.6$, $\mathrm{c} 2=1000, \mathrm{c} 3=-2.5, \mathrm{c} 4=1225, \mathrm{c} 5=-376$ )

2. The $\Delta \mathrm{Keff}$, so the crack propagation rate, can be estimated from conclusion 1 .

3. The constant- $\Delta$ Keff test is effective for the quantitative analysis of the correlation of the residual stress on the fatigue fractured surface and the fracture mechanics parameters.

\section{REFERENCES}

${ }^{1}$ H.Kitagawa and T.Matsumoto, J.S.M.E.,41, p.22 (1975)

2 A.Komine, E.Nakanishi and K.Komine, J.S.M.S., 27, p.245 (1978)

${ }^{3}$ Y.Kurebayashi, S.Kodama, H.Misawa, J.S.M.S., 33, p. 1039 (1984)

${ }^{4}$ M.Kikukawa, M.Jono, K.Tanaka and M.Takatani, J.S.M.S., 25, p.899 (1976)

This paper was presented in the International Satellite Conference on Mechanical Characterization of New Materials at Tokai University, July 19, 20, 1991. 